BMJ Open Sport \& Exercise Medicine

\title{
Knee strength, hop performance and self-efficacy at 4 months are associated with symmetrical knee muscle function in young athletes 1 year after an anterior cruciate ligament reconstruction
}

\author{
Susanne Beischer, ${ }^{\oplus 1,2}$ Eric Hamrin Senorski, ${ }^{\oplus 1,2}$ Christoffer Thomeé, ${ }^{1}$ \\ Kristian Samuelsson, ${ }^{3,4}$ Roland Thomeé ${ }^{1,2}$
}

To cite: Beischer $\mathrm{S}$ Hamrin Senorski E, Thomeé C, et al. Knee strength, hop performance and self-efficacy at 4 months are associated with symmetrical knee muscle function in young athletes 1 year after an anterior cruciate ligament reconstruction. BMJ Open Sport \& Exercise Medicine 2019;5:e000504. doi:10.1136/ bmjsem-2018-000504

Accepted 31 January 2019
Check for updates

(c) Author(s) (or their employer(s)) 2019. Re-use permitted under CC BY-NC. No commercial re-use. See rights and permissions. Published by BMJ.

${ }^{1}$ Sportrehab Sports Medicine Clinic, Gothenburg, Sweden ${ }^{2}$ Section of Physiotherapy, Department of Health and Rehabilitation, Institute of Neuroscience and Physiology, Gothenburg, Sweden ${ }^{3}$ Department of Orthopaedics, Institute of Clinical Sciences, Gothenburg, Sweden ${ }^{4}$ Department of Orthopaedics, Sahlgrenska University Hospital, Mölndal, Sweden

Correspondence to Susanne Beischer; susanne.beischer@gu.se

\section{ABSTRACT}

Objectives We investigated whether patient demographics, 4-month patient-reported outcomes (PRO) and muscle function predicted young athletes regaining symmetrical muscle function in five tests of muscle function 1 year after ACL reconstruction

Methods We extracted data on patient demographics, PROs and the results of five tests of muscle function from a rehabilitation-specific register. Athletes were 15-30 years of age, involved in knee-strenuous sport and had undergone a primary ACL reconstruction. The primary outcome was achieving a Limb Symmetry Index of $\geq 90 \%$ for the battery of tests 1 year after ACL reconstruction. Patient demographics, muscle-function data and results for PROs at the 4-month follow-up were analysed.

Results In all, 237 athletes (59\% female; mean age $22 \pm 4$ years) were included in the study. One year after ACL reconstruction, 26\% (62/237) of the included athletes had achieved symmetrical muscle function. Univariable analysis showed that symmetrical muscle function was associated with present self-efficacy, OR $1.28(95 \% \mathrm{Cl} 1.04$ to $1.58, p=0.011)$, knee-extension strength, OR $1.73(95 \%$ $\mathrm{Cl} 1.28$ to 2.34), knee-flexion strength, OR $1.39(95 \% \mathrm{Cl}$ 1.07 to 1.81$)$, vertical hop, OR 1.77 (95\% Cl 1.27 to 2.45$)$, single-leg hop for distance, OR $1.98(95 \% \mathrm{Cl} 1.24$ to 3.17$)$ and side hop, OR 1.64 (95\% Cl 1.15 to 2.33).

Conclusion Symmetrical knee-extension and kneeflexion strength, a more symmetrical hop performance and higher present self-efficacy at an early stage all increased the odds of achieving symmetrical muscle function in young athletes 1 year after ACL reconstruction.

\section{INTRODUCTION}

After an anterior cruciate ligament (ACL) reconstruction, athletes who have regained symmetrical muscle function have lower risk of a subsequent ACL injury than those who continue to have asymmetry. ${ }^{12}$ In young athletes, 15-30 years of age, a minority regain symmetrical muscle function before returning to sport after a primary ACL

\section{What are the findings?}

Young athletes with more symmetrical knee-extension and knee-flexion strength, a more symmetrical hop performance and higher present self-efficacy, early after ACL reconstruction, have increased odds of achieving symmetrical muscle function 1 year after ACL reconstruction.

- Only one in four young athletes achieves symmetrical muscle function 1 year after ACL reconstruction.

How might it impact on clinical practice in the future?

- Clinicians should inform athletes not to return to sport before symmetrical muscle function is achieved.

- To set realistic expectations, athletes with asymmetrical knee muscle function and lower present self-efficacy 4 months after ACL reconstruction should be informed that achieving symmetrical muscle function may take longer than 1 year.

reconstruction. ${ }^{3}{ }^{4}$ This is a challenge for clinicians, as young individuals have a high reinjury risk after ACL reconstruction, where one-fourth of patients younger than 25 years of age sustain a second ACL injury once they return to sport (RTS). ${ }^{5-10}$

Symmetrical muscle function is a cornerstone of rehabilitation after an ACL injury as it is associated with a higher rate of RTS. ${ }^{11}$ Moreover, Toole $e t a \hat{l}$ reported that a greater proportion of athletes, who have symmetrical knee strength at time of RTS, maintained the same level of sports participation over the year following the RTS, compared with those who do not meet the criteria. ${ }^{3}$ We see clinical value in finding modifiable factors early in the rehabilitation that predict the 
recovery of symmetrical muscle function prior to RTS. A better understanding of patient characteristics as well as of modifiable factors is important to set realistic expectations and goals for patients and optimise rehabilitation. However, knowledge relating to these factors is limited in young athletes.

Many factors probably contribute to the achievement of symmetrical muscle function. Patients who early have lower levels of pain and symptoms, less associated problems and a more symmetrical muscle function may be better off when it comes to recovering symmetrical muscle function at 1 year after the ACL reconstruction. ${ }^{12-16}$ Moreover, psychological outcomes, such as self-efficacy, that is, how certain an individual is about his/her own ability to perform an activity despite pain or discomfort, might be important, as an association between self-efficacy and symmetrical hop performance has been reported in patients after an ACL reconstruction. ${ }^{17}$ However, our knowledge of psychological outcomes as predictors is limited, specifically in young ACL patients.

The objective of this study was to investigate whether patient demographics, short-term patient-reported outcomes (PRO) and muscle function are able to predict the achievement of symmetrical muscle function in five tests of muscle function in young athletes 1 year after ACL reconstruction. The hypothesis was that adolescent athletes, who perceived higher levels of self-efficacy and self-reported knee function, and athletes with more symmetrical muscle function at 4 months after ACL reconstruction would have higher odds of achieving symmetrical muscle function 1 year after reconstruction.

\section{MATERIALS AND METHODS}

This study was performed as a prospective cohort study based on data from a rehabilitation outcome register, Project ACL. ${ }^{418}$ All the athletes (patients) were given written information about the study and informed consent was obtained. The data have been coded and none of the included athletes could be identified during analyses.

Project ACL includes patients with an ACL injury irrespective of their age, sex, time from injury or choice of treatment. The project uses a web-based platform for regular assessments with PROs and muscle function, according to a predefined schedule of follow-ups after the latest ACL injury or reconstruction.

\section{Patients}

Patients who had sustained a unilateral ACL injury and undergone ACL reconstruction between 1 April 2013 and 1 April 2017 were eligible for inclusion. Patients were included in the study if they were between 15 and 30 years of age and had data from the 4-month follow-up, including PROs and/or tests of muscle function, and had performed all tests of muscle function 1 year after the ACL reconstruction. A further inclusion criterion was that the patients were regarded as athletes, defined as having participated in knee-strenuous sport before sustaining their ACL injury, that is, a preinjury Tegner Activity Scale (Tegner) of $\geq 6$. ${ }^{19}$

\section{Predictors}

The included athletes were evaluated with regard to PROs and with tests of muscle function at the 4-month follow-up and at 1 year after the ACL reconstruction. All the patient demographics were self-reported.

\section{Patient-reported outcomes}

To assess the preinjury and present level of physical activity, the Tegner was used. ${ }^{14}$ The Tegner has acceptable test-retest reliability, with an intraclass correlation coefficient (ICC) of 0.8 for patients with an ACL injury or reconstruction. ${ }^{19} 20$

To assess perceived knee-related self-efficacy, that is, how certain a patient is about the performance of knee activities in the present and in the future, a shorter version of the Knee Self-Efficacy Scale (K-SES) was used. ${ }^{21}$ The shorter version contains 4 items less than the original K-SES and some items are somewhat rephrased. Reliability, structure and validity is the same or better (unpublished data). ${ }^{21}$

The Knee injury and Osteoarthritis Outcome Score $(\mathrm{KOOS})^{22}$ was used to assess patients' opinions of their knee and associated problems after ACL reconstruction. The KOOS has been reported to have acceptable test-retest reliability, with an ICC ranging from 0.85 to 0.93 for each of the five subscales in patients with an ACL injury or reconstruction. ${ }^{22}$ In the present study, the $\mathrm{KOOS}_{4}$, an average score of the four subscales of pain, knee-related symptoms, function in sport and recreation and knee-related quality of life, was used. In the $\mathrm{KOOS}_{4}$, the dimension of function throughout daily living is excluded to avoid ceiling effects due to the fact that relatively young and active patients rarely have difficulty with activities of daily living. ${ }^{23}$

\section{Tests of muscle function}

Table 1 shows the detailed information on the test procedure. $^{424}$ The test procedure, including the warm-up procedure, familiarisation and maximum repetitions in both strength and hop tests, has been described in previous studies. ${ }^{424}$

At the start of Project ACL, isometric tests of knee extension and knee flexion were performed using David F200 DMS-EVE (David Health Solutions, 2013, Finland). These results contribute about $20 \%$ of the total muscle strength data in the present study. The isometric tests were then replaced by isokinetic concentric strength tests of knee extension and knee flexion using Biodex System 4 (Biodex Medical Systems, Shirley, New York, USA). Both devices have been reported to have high reliability. ${ }^{25-28}$

After strength testing, three hop tests were performed in the following order: unilateral vertical hop, unilateral hop for distance and unilateral side hop. High test-retest 
Table 1 Tests of muscle function

\begin{tabular}{|c|c|c|c|c|}
\hline & Knee angles $\left({ }^{\circ}\right)$ & $\begin{array}{l}\text { Practice trials, } n \\
\text { (\% of } 1 \mathrm{RM})\end{array}$ & $\begin{array}{l}\text { Maximum } \\
\text { repetitions (n) }\end{array}$ & $\begin{array}{l}\text { Rest between } \\
\text { repetitions (s) }\end{array}$ \\
\hline \multicolumn{5}{|l|}{ Knee extension } \\
\hline Isometric* & 60 & $3(70,80,90 \%$ of $1 \mathrm{RM})$ & $3-5$ & 40 \\
\hline Isokinetic $†$ & $0-90$ & $1-2(90 \%$ of $1 \mathrm{RM})$ & & \\
\hline \multicolumn{5}{|l|}{ Knee flexion } \\
\hline Isometric $\ddagger$ & 60 & $3(70,80,90 \%$ of $1 \mathrm{RM})$ & $3-5$ & 40 \\
\hline Isokinetic $†$ & $0-90$ & $1-2(90 \%$ of $1 \mathrm{RM})$ & & \\
\hline Unilateral vertical hop§ & - & 2 & 3 & 20-30 \\
\hline Single-leg hop for distance & - & 2 & 3 & 20-30 \\
\hline Side hop & - & 10 & 1 & 360 \\
\hline
\end{tabular}

*Measured with David F200 DMS-EVE (David Health Solutions, 2013, Finland).

†Measured with Biodex System 4 (Biodex Medical Systems, Shirley, New York, USA) at 90\% s.

¥Measured with David F300 DMS-EVE (David Health Solutions, 2013, Finland).

$\S$ Measured with MuscleLab, Ergotest Technology, Oslo, Norway.

TAs many hops as possible in $30 \mathrm{~s}$ over two lines, $40 \mathrm{~cm}$ apart.

$\mathrm{RM}$, repetition maximum.

reliability for the three different tests in the battery of hop tests has been reported (ICC 0.93-0.97). ${ }^{29}$

\section{Outcome}

In the present study, achieving a Limb Symmetry Index (LSI) of $\geq 90 \%$ in all five tests of muscle function was defined as the achievement of symmetrical muscle function $^{30}$ and was used as the primary outcome. The LSI is defined as the ratio between the results for the injured side and the non-injured side expressed as a percentage.

\section{Statistical analysis}

Statistical analysis was performed using the Statistical Analysis System (SAS/STAT, V.14.2, 2016; SAS Institute).

Descriptive statistics were reported as count and proportion, as the median with minimum and maximum or as the mean with SD. Comparisons between groups were performed using Fisher's exact test (lowest one-sided $p$ value multiplied by 2 ) for dichotomous variables, while the Mantel-Haenszel $\chi^{2}$ test was used for ordered categorical variables. The $\chi^{2}$ test was used for non-ordered categorical variables and the Mann-Whitney $U$ test was used for continuous variables.

Binary logistic regression was performed to analyse the association between the independent variables and the primary outcome, that is, the achievement of symmetrical knee muscle function 1 year after ACL reconstruction.

Finally, a forward stepwise multivariable logistic model including all independent variables was used to predict the achievement of symmetrical muscle function at 1 year. A secondary model, excluding the three hop tests, was also performed. In this second analysis, knee extension symmetry was entered first, based on previous publications. ${ }^{1216-21}$ The variables which had a $p$ value of $<0.20$ in the univariable analyses were entered in the two stepwise regression models, where the variable with the highest area under the receiver operating characteristics (ROC) curve was entered first.

The results from the logistic regression models were presented with an OR, that is, the ratio between the odds of an increase in the predictor, 95\% CIs and $p$ values. The area under the ROC curve was given as a measurement of goodness of fit, using limits of $0.90-1=$ excellent, $0.80-0.90=$ good, $\quad 0.70-0.80=$ fair, $0.60-0.70=$ poor and $0.50-0.60=$ fail. ${ }^{31}$ All significance tests were conducted at the $5 \%$ significance level.

\section{RESULTS}

A total of 237 athletes $(59 \%$ female; mean age $22 \pm 4$ years) were included in the study (figure 1). Moreover, 122 athletes were excluded because they were not able to perform any of the hop tests and 31 athletes were excluded as they only performed one or two hop tests. There were no differences in patient demographics at the 4-month follow-up between included and excluded athletes (table 2).

In all, 26\% (62/237) had achieved symmetrical muscle function 1 year after ACL reconstruction. At the 4-month follow-up, male athletes had significantly higher $\mathrm{K}_{-S E S}{ }_{\text {present }}$ (difference in medians: 1 unit, $\mathrm{p}<0.0002$ ) and higher KOOS $($ difference in means: 5.5 units, $\mathrm{p}=0.011$ ) compared with female athletes, table 3. Moreover, male athletes had a higher LSI in the single-leg hop for distance (difference in means: $8.2 \mathrm{~cm}, \mathrm{p}=0.0054$ ) compared with female athletes.

\section{Univariable analyses}

ORs, CIs and $\mathrm{p}$ values for the tested variables are summarised in table 4 and figure 2 . None of the patient demographics were found to be significant when attempting to predict the achievement of symmetrical muscle function 1 year after ACL reconstruction. Athletes 


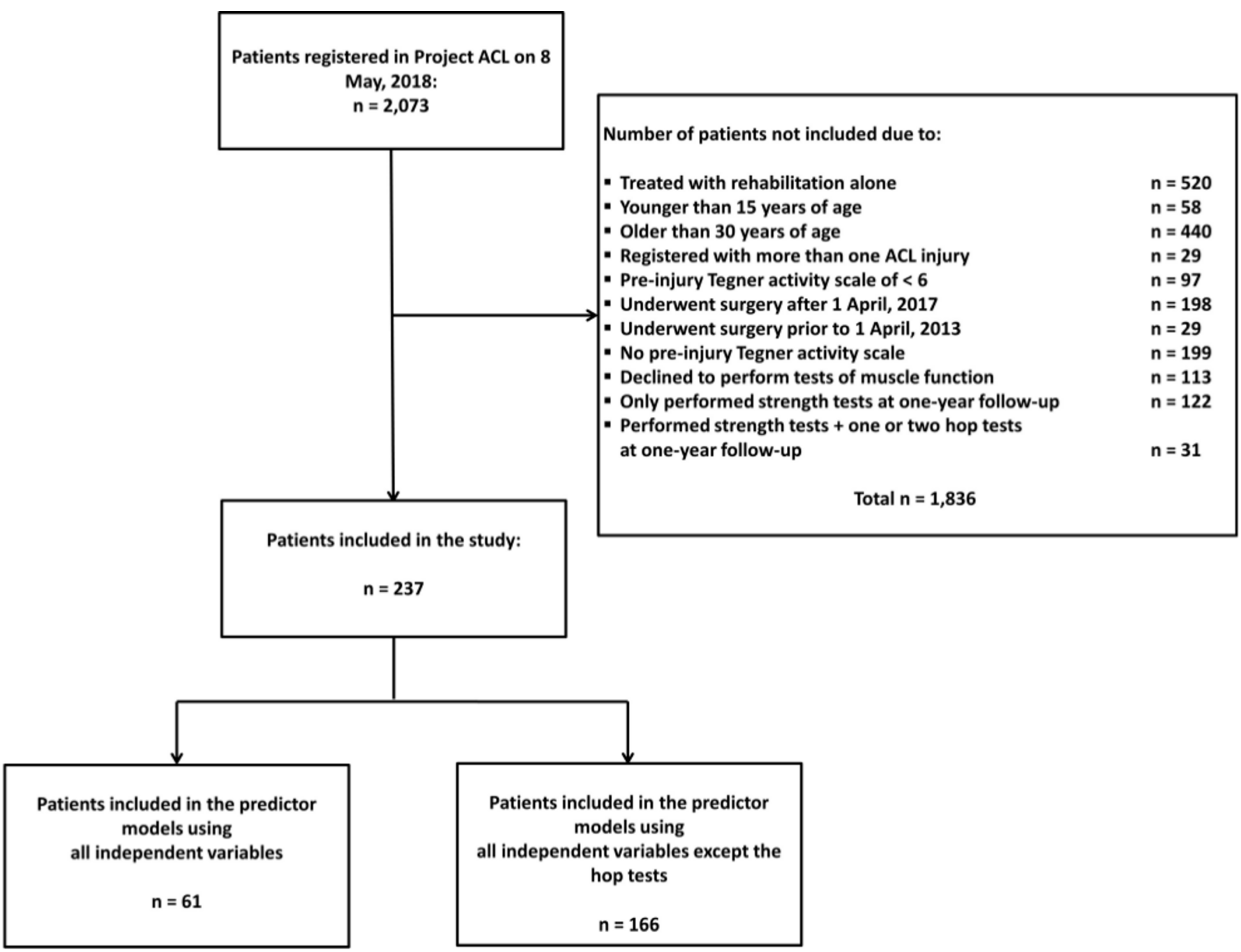

Figure 1 Flow chart of inclusion and exclusion.

with higher self-efficacy at 4 months had increased odds for symmetrical muscle function at 1 year after ACL reconstruction; K-SES ${ }_{\text {present, }}$ OR 1.28 (95\% CI 1.04 to $1.58, \mathrm{p}=0.020)$. Moreover, increased odds for achieving symmetrical muscle function were found in athletes with more symmetrical knee-extension strength, OR 1.73 (95\% CI 1.28 to 2.34, $\mathrm{p}=0.0004$ ) and knee-flexor strength, OR 1.39 (95\% CI 1.07 to $1.81, p=0.015)$. In terms of hop tests, increased odds were found in athletes with more symmetrical hop performance in the vertical hop, OR 1.77 (95\% CI 1.27 to $2.45, \mathrm{p}=0.0006$ ), the single-leg hop for distance, OR 1.98 (95\% CI 1.24 to $3.17, \mathrm{p}=0.0043$ ) and the side hop, OR 1.64 (95\% CI 1.15 to 2.33, $\mathrm{p}=0.0059$ ).

\section{Multivariable analyses}

A total of 61 athletes were able to perform all five tests of muscle function at the 4-month follow-up and were included in the multivariable analysis to predict the achievement of symmetrical knee muscle function 1 year after ACL reconstruction. No predictive multivariable model could be created because of data missing from hop tests and the small number of patients who had achieved the dependent outcome of symmetrical muscle function.
When excluding athletes with missing data (hop tests, $\mathrm{n}=105$ ) from the three hop tests at 4 months, a total of 166 athletes were included in the second multivariable model. No combinations of variables were significant when performing the multivariable model.

\section{DISCUSSION}

The principal findings in this study were that more symmetrical knee-extension and knee-flexion strength, a more symmetrical hop performance and higher present self-efficacy, 4 months after ACL reconstruction, were associated with symmetrical muscle function in young athletes at 1 year. In addition, just over one in four of the athletes had recovered their muscle function, defined as an LSI of $\geq 90 \%$ in all five muscle function tests 1 year after the ACL reconstruction.

A multivariable logistic model, including all the independent variables from the 4-month follow-up after ACL reconstruction, was not created, as only 19 of the total of 61 athletes had complete data from all independent variables and had achieved symmetrical muscle function at 1 year. Creating a multivariable model based on these 
Table 2 Baseline demographics and dropout analysis for included and excluded patients

\begin{tabular}{|c|c|c|c|c|}
\hline & $\begin{array}{l}\text { Eligible } \\
(\mathrm{n}=390)\end{array}$ & $\begin{array}{l}\text { Included } \\
(n=237)\end{array}$ & $\begin{array}{l}\text { Excluded } \\
(\mathrm{n}=153)\end{array}$ & P value* \\
\hline \multicolumn{5}{|l|}{ Patient sex } \\
\hline Female & $236(60.5 \%)$ & 139 (58.6\%) & 97 (63.4\%) & 0.41 \\
\hline Height (cm) & $174.0(150.0 ; 200.0)$ & $174.0(150.0 ; 200.0)$ & $175.0(155.0 ; 197.0)$ & 0.21 \\
\hline Weight (kg) & $70.0(45.0 ; 118.0)$ & $70.0(45.0 ; 102.0)$ & $72.0(49.0 ; 118.0)$ & 0.091 \\
\hline BMI $\left(\mathrm{kg} / \mathrm{m}^{2}\right)$ & $23.3(17.9 ; 38.7)$ & $23.1(18.5 ; 35.4)$ & $23.9(17.9 ; 38.7)$ & 0.099 \\
\hline Age at index surgery & $21.7(4.3)$ & $21.5(4.2)$ & $22.1(4.4)$ & 0.18 \\
\hline \multicolumn{5}{|c|}{ Preinjury physical activity level† } \\
\hline $6(\%)$ & $22(6)$ & $13(6)$ & $9(6)$ & \\
\hline $7(\%)$ & $58(15)$ & $33(14)$ & $25(16)$ & \\
\hline $8(\%)$ & $116(30)$ & $71(30)$ & $45(29)$ & \\
\hline $9(\%)$ & $136(35)$ & $82(35)$ & $54(35)$ & \\
\hline $10(\%)$ & $58(15)$ & $38(16)$ & $20(13)$ & 0.45 \\
\hline \multicolumn{5}{|l|}{ Graft choice } \\
\hline Hamstring (\%) & $285(85.1)$ & $190(86.0)$ & 95 (83.3) & \\
\hline Patella (\%) & $42(12.5)$ & 27 (12.2) & $15(13.2)$ & \\
\hline Allograft (\%) & $5(1.5)$ & $3(1.4)$ & $2(1.8)$ & \\
\hline Other graft (\%) & $2(0.6)$ & $1(0.5)$ & $1(0.9)$ & 0.67 \\
\hline
\end{tabular}

For categorical variables, $\mathrm{n}(\%)$ is presented.

Patient's height, weight and BMI are presented as the median (min; max).

Patient's age at index surgery is presented as the mean (SD).

For comparisons between groups, Fisher's exact test (lowest one-sided $p$ value multiplied by 2) was used for dichotomous variables, the $\chi^{2}$ test was used for non-ordered categorical variables and the Mann-Whitney $U$ test was used for continuous variables.

${ }^{*}$ Comparison between included and excluded patients.

†As measured with the Tegner Activity Scale.

BMI, body mass index.

19 events would have resulted in an overfitted model and thereby an unreliable result. ${ }^{32}$ When we excluded the hop tests as independent variables, it became impossible to create a predictive multivariable model for symmetrical muscle function 1 year after ACL reconstruction as the inclusion of any other variable resulted in a non-significant model.

\section{Demographics}

Younger age and being male are both associated with better outcome, in terms of RTS and perceived knee

Table 3 Four-month outcome (independent variable) and between-group analysis between female and male athletes

\begin{tabular}{|c|c|c|c|c|}
\hline & $\begin{array}{l}\text { Included } \\
(n=237)\end{array}$ & $\begin{array}{l}\text { Female } \\
(n=139)\end{array}$ & $\begin{array}{l}\text { Male } \\
(n=98)\end{array}$ & P value* \\
\hline K-SES & $6.3(1.6 ; 9.7) n=176$ & $6.1(1.6 ; 9.1) n=110$ & $7.1(2.1 ; 9.7) n=66$ & 0.0002 \\
\hline K-SES & $7.8(0.0 ; 10.0) n=176$ & $7.8(3.0 ; 10.0) n=110$ & $8.0(0.0 ; 10.0) n=66$ & 0.084 \\
\hline $\mathrm{KOOS}_{4}$ & $63.4(13.2) n=176$ & $61.3(13.2) n=110$ & $66.8(12.4) n=66$ & 0.011 \\
\hline LSI knee extensor (\%) & $82.5(15.5) n=166$ & $80.3(16.1) n=102$ & $86.1(13.8) n=64$ & 0.066 \\
\hline LSI knee flexor (\%) & $92.6(14.3) n=166$ & $92.2(14.2) n=102$ & $93.3(14.4) n=64$ & 0.83 \\
\hline LSI vertical hop (\%) & $82.6(74.8) n=96$ & $86.3(102.5) n=50$ & $78.7(18.5) n=46$ & 0.16 \\
\hline LSI hop for distance (\%) & $82.7(15.7) n=90$ & $78.5(16.2) n=44$ & $86.7(14.3) n=46$ & 0.0054 \\
\hline LSI side hop (\%) & $80.2(23.3) n=61$ & $77.2(23.6) n=27$ & $82.5(23.2) n=34$ & 0.21 \\
\hline
\end{tabular}

$\mathrm{K}_{-S E S}$ present $_{\text {and K-SES }}$ future are presented as the median (min; max).

The KOOS and the results of muscle function tests are presented as the mean (SD).

For comparisons between groups the Mann-Whitney $U$ test was used for continuous variables.

${ }^{*}$ Comparison between females and males.

KOOS, Knee injury and Osteoarthritis Outcome Score; K-SES, Knee Self-Efficacy Scale;LSI, Limb Symmetry Index. 
Table 4 Univariable logistic regression model with muscle function recovery as the dependent outcome*

\begin{tabular}{|c|c|c|c|c|c|c|}
\hline \multirow[b]{2}{*}{ Variable } & \multirow[b]{2}{*}{ Missing (n) } & \multirow[b]{2}{*}{ Value } & \multirow[b]{2}{*}{$\begin{array}{l}\text { Muscle function } \\
\text { recovery (1 year) }\end{array}$} & \multicolumn{3}{|l|}{ Univariable } \\
\hline & & & & $\begin{array}{l}\text { OR }(95 \% \mathrm{Cl}) \\
\text { Muscle function } \\
\text { recovery (1 year) }\end{array}$ & $P$ value & $\begin{array}{l}\text { Area under ROC curve } \\
(95 \% \mathrm{Cl})\end{array}$ \\
\hline \multirow[t]{2}{*}{ Patient sex } & 0 & Female & $32(23.0 \%)$ & & & \\
\hline & & Male & $30(30.6 \%)$ & $1.48(0.82$ to 2.64$)$ & 0.19 & 0.55 (0.48 to 0.62$)$ \\
\hline \multirow[t]{3}{*}{ Height (cm) (OR per 10 units) } & 0 & 150 to $<170$ & $17(22.4 \%)$ & & & \\
\hline & & 170 to $<179$ & $22(25.3 \%)$ & & & \\
\hline & & $179-200$ & $23(31.1 \%)$ & $1.30(0.96$ to 1.78$)$ & 0.094 & $0.56(0.48$ to 0.65$)$ \\
\hline \multirow[t]{3}{*}{ Weight (kg) (OR per 10 units) } & 0 & 45 to $<66$ & $20(24.4 \%)$ & & & \\
\hline & & 66 to $<76$ & $19(23.5 \%)$ & & & \\
\hline & & $76-102$ & $23(31.1 \%)$ & 1.19 (0.92 to 1.55$)$ & 0.18 & 0.55 (0.47 to 0.64$)$ \\
\hline \multirow[t]{2}{*}{ Age (dichotomised) } & 0 & $15-20$ & $26(22.2 \%)$ & & & \\
\hline & & $21-30$ & $36(30.0 \%)$ & 1.50 (0.84 to 2.69$)$ & 0.17 & 0.55 (0.48 to 0.62$)$ \\
\hline \multirow[t]{5}{*}{ Tegner preinjury } & 0 & 6 & 5 (38.5\%) & & & \\
\hline & & 7 & $14(42.4 \%)$ & & & \\
\hline & & 8 & $8(11.3 \%)$ & & & \\
\hline & & 9 & $24(29.3 \%)$ & & & \\
\hline & & 10 & $11(28.9 \%)$ & $0.93(0.71$ to 1.21$)$ & 0.59 & 0.51 (0.42 to 0.59$)$ \\
\hline \multirow[t]{3}{*}{$\mathrm{KOOS}_{4}$ (OR per 10 units) } & 61 & 24 to $<58$ & $17(29.3 \%)$ & & & \\
\hline & & 58 to $<70$ & $11(18.6 \%)$ & & & \\
\hline & & $70-93$ & $20(33.9 \%)$ & 1.17 (0.90 to 1.52$)$ & 0.23 & 0.54 (0.45 to 0.64$)$ \\
\hline \multirow[t]{3}{*}{ K-SES ${ }_{\text {present }}$} & 61 & 1.6 to $<5.5$ & $12(21.4 \%)$ & & & \\
\hline & & 5.5 to $<7$ & $15(25.4 \%)$ & & & \\
\hline & & $7-9.7$ & $21(34.4 \%)$ & 1.28 (1.04 to 1.58$)$ & 0.020 & 0.60 (0.51 to 0.69$)$ \\
\hline \multirow[t]{3}{*}{ K-SES ${ }_{\text {future }}$} & 61 & 0 to $<5.5$ & $6(27.3 \%)$ & & & \\
\hline & & 5.5 to $<7$ & $9(28.1 \%)$ & & & \\
\hline & & $7-10$ & $33(27.0 \%)$ & $1.03(0.85$ to 1.24$)$ & 0.79 & $0.52(0.42$ to 0.62$)$ \\
\hline \multirow[t]{2}{*}{ Graft choice } & 20 & Hamstring & $52(27.4 \%)$ & & & \\
\hline & & Patella & $6(22.2 \%)$ & 0.76 (0.29 to 1.98$)$ & 0.57 & 0.51 (0.47 to 0.56$)$ \\
\hline \multirow[t]{3}{*}{ LSI knee extension (OR per 10 units) } & 71 & 38 to $<79$ & $6(9.8 \%)$ & & & \\
\hline & & 79 to $<90$ & $15(31.3 \%)$ & & & \\
\hline & & $90-153$ & $26(45.6 \%)$ & 1.73 (1.28 to 2.34$)$ & 0.0004 & $0.69(0.61$ to 0.77$)$ \\
\hline \multirow[t]{2}{*}{ LSI knee flexion (OR per 10 units) } & 71 & 42 to $<90$ & $15(21.7 \%)$ & & & \\
\hline & & $90-141$ & $32(33.0 \%)$ & 1.39 (1.07 to 1.81$)$ & 0.015 & $0.62(0.52$ to 0.71$)$ \\
\hline \multirow[t]{3}{*}{ LSI vertical hop (OR per 10 units) } & 141 & 35 to $<65$ & $1(3.7 \%)$ & & & \\
\hline & & 65 to $<90$ & $18(36.0 \%)$ & & & \\
\hline & & $90-149$ & $9(47.4 \%)$ & $1.77(1.27-2.45)$ & 0.0006 & 0.75 (0.64 to 0.85$)$ \\
\hline \multirow[t]{3}{*}{ LSI hop for distance (OR per 10 units) } & 147 & 37 to $<81$ & $4(13.3 \%)$ & & & \\
\hline & & 81 to $<90$ & $8(28.6 \%)$ & & & \\
\hline & & $90-106$ & $13(40.6 \%)$ & $1.98(1.24$ to 3.17$)$ & 0.0043 & $0.72(0.60$ to 0.84$)$ \\
\hline \multirow[t]{3}{*}{ LSI side hop (OR per 10 units) } & 176 & 25 to $<69$ & $2(11.1 \%)$ & & & \\
\hline & & 69 to $<90$ & $4(21.1 \%)$ & & & \\
\hline & & $90-125$ & $13(54.2 \%)$ & 1.64 (1.15 to 2.33$)$ & 0.0059 & $0.74(0.61$ to 0.87$)$ \\
\hline
\end{tabular}

$\mathrm{OR}$ is the ratio for the odds of an increase in the predictor of 1 unit.

Muscle function recovery achieving an LSI of $\geq 90 \%$ in all five tests included in the battery of tests.

All tests are performed with univariable logistic regression.

$P$ values, OR and area under the receiver operating characteristics $(R O C)$ curve are based on original values and not on stratified groups.

*Achieving an LSI of $\geq 90 \%$ in five tests of muscle function.

KOOS, Knee injury and Osteoarthritis Outcome Score; K-SES, Knee Self-Efficacy Scale; LSI, Limb Symmetry Index; ROC, receiver operating characteristics. 


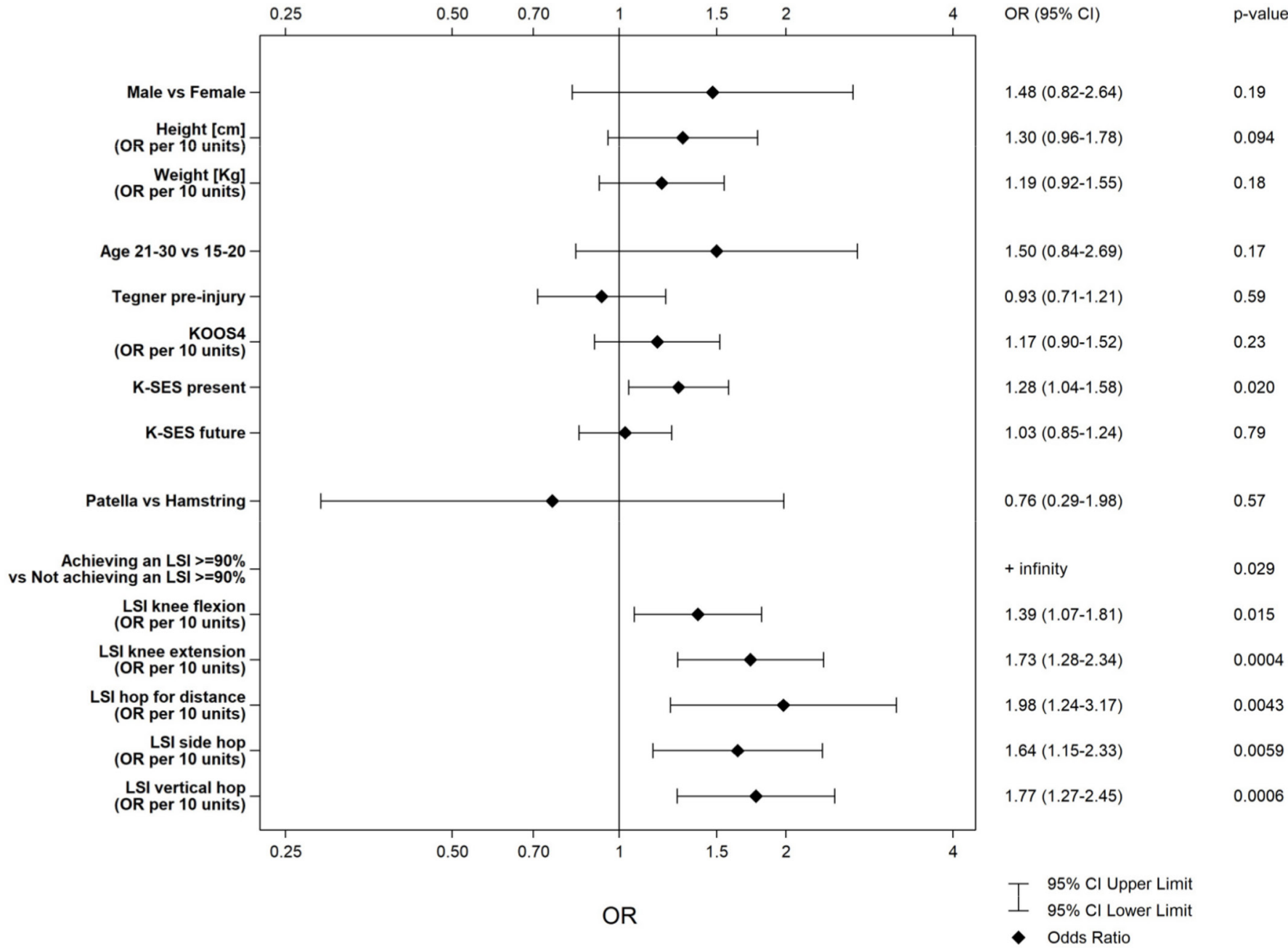

Figure 2 Univariable logistic regression models, ORs and 95\% Cls for muscle function recovery, defined as achieving a Limb Symmetry Index of $\geq 90 \%$ in five tests of muscle function 1 year after an ACL reconstruction. For patient sex, an OR of $>1$ indicates a result favouring males. For age at primary ACL reconstruction, an OR of $>1$ favours the older age group (21-30 years old). For graft choice, an OR of $>1$ indicates a result favouring patellar tendon autografts. $\mathrm{KOOS}_{4}$, Knee Osteoarthritis Outcome Score (four dimensions); K-SES future $_{\text {, future Knee Self-Efficacy Scale; K-SES }}$ present' , present Knee Self-Efficacy Scale; LSI, Limb Symmetry Index; Tegner preinjury, Tegner Activity Scale prior to the injury.

function. ${ }^{33-35}$ There are conflicting results related to age as a predictor of achieving symmetrical muscle function in a battery of tests in previous studies. ${ }^{246}$ However, none of the patient demographics were found to be associated with the achievement of symmetrical muscle function in the present study.

\section{Patient-reported outcomes}

In the present study, the psychological outcome of self-efficacy was associated with regaining symmetrical muscle function; this extends findings from a previous study ${ }^{17}$ where higher levels of preoperative self-efficacy were associated with achieving symmetrical muscle function in the single-leg hop for distance. According to the theory of self-efficacy, ${ }^{37}$ a person with high self-efficacy who confronts a setback will increase his/her level of effort and persistence. We assumed that athletes with high self-efficacy would be more motivated to participate in, and be compliant with, rehabilitation and therefore have greater potential to achieve more symmetrical muscle function compared with athletes with low self-efficacy. This is the first study investigating the association between self-efficacy and symmetrical muscle function across a battery of tests. However, this result must be considered with caution, as the area under the ROC curve was 0.60 , meaning that the predictive value of this model is poor. ${ }^{31}$ This is one of the first studies to use psychological outcomes as predictors of symmetrical muscle function. Future studies are needed to further evaluate the association between early psychological outcome and symmetrical muscle function.

\section{Muscle function}

In the present study, all three hop tests were associated with symmetrical muscle function 1 year after ACL reconstruction. The areas under the ROC varied between 0.72 and 0.75 for all three models, indicating that these models had a fair goodness of fit. ${ }^{31}$

The finding that single-leg hop tests are associated with enhanced outcome has previously been reported in the 
literature. Logerstedt $e t a \hat{l}^{8}$ reported that single-leg hop tests, conducted at 6 months after ACL reconstruction, were associated with self-reported knee function 1 year after surgery. Interestingly, more than $50 \%$ of the athletes in the present study who were already able to perform a symmetrical side hop at the 4-month follow-up achieved symmetrical muscle function 1 year after the ACL reconstruction. However, about $40 \%$ of the included patients who had performed the knee strength tests on both follow-up occasions $(n=166)$ were able to perform all three hop tests as early as 4 months after the reconstruction. This finding could, however, be expected as many rehabilitation protocols recommend beginning with hop exercises at about 4 months after reconstruction. ${ }^{39-41}$ In addition, this finding provides valuable information for all clinicians and athletes in order to set realistic expectations during rehabilitation and highlights the fact that not all patients will be able to perform hop tests early in their rehabilitation. In comparison, 61\% (237/390) of the athletes who were evaluated with tests of muscle function 1 year after the ACL reconstruction were able to perform all three hop tests (figure 1).

The finding that knee-extension strength was associated with symmetrical muscle function in all five tests of muscle function confirms the findings reported by Hartigan et $a l,{ }^{36}$ who reported that patients with more symmetrical isometric knee-extension strength preoperatively predicted the fulfilment of their RTS criteria, including strength and hop tests, 6 months after ACL reconstruction. In addition, Nawasreh et al ${ }^{11}$ reported that patients who pass their RTS criteria, including tests of muscle function and PROs, 6 months after ACL reconstruction, continued to maintain higher knee function, compared with patients who did not fulfil the criteria early in the rehabilitation process. However, in the present study, the area under the ROC was 0.69 for the effect of knee-extension strength on achieving symmetrical knee function, which corresponds to a poor goodness of fit. ${ }^{31}$

In the present study, almost $40 \%$ of the athletes who had an LSI of $80 \%$ or higher in knee extension at 4 months following the reconstruction achieved symmetrical muscle function at 1 year compared with fewer than $10 \%$ of the athletes who had an LSI lower than $80 \%$. This finding suggests that patients who have a deficit in knee-extension strength of more than $20 \%$ early after ACL reconstruction may need more than 1 year of rehabilitation to achieve symmetrical muscle function. Considering the positive effects of better short-term outcomes in terms of enhanced self-reported function ${ }^{12131516}$ and enhanced muscle function, ${ }^{42-45}$ clinicians are recommended to focus on optimising knee-extension strength during the entire rehabilitation process.

\section{Limitations and strengths}

This prospective cohort study has some limitations that were taken into account before conclusions were drawn. First, a minority of the athletes who performed the tests of muscle function were able to perform all three hop tests at the 4-month follow-up. This resulted in an overly limited population and a multivariable model could therefore not be created.

Second, as two different tests to assess the athletes' muscle strength were used, we chose not to analyse the absolute value for each test in the statistical analysis. The outcomes from the two methods are regarded as comparable, as they are presented as an LSI. However, the use of the LSI has some limitations in itself. ${ }^{46}{ }^{47}$ Since the LSI is calculated as a ratio between the values for the injured and uninjured legs and deficits in strength are common in both legs after ACL reconstruction, the LSI might underestimate muscle function requirements. ${ }^{46} 48$

This is the first study to investigate predictors of achieving symmetrical muscle function in young athletes, 15-30 years old, after ACL reconstruction. A large population of 237 young athletes was included with results generalisable to a large extent to the general ACL population, as the included athletes did not differ from the excluded 153 athletes. Moreover, the methods used for assessing strength and hop performance, as well as the PROs that were used, have all been reported to be reliable and valid for evaluating patients after an ACL reconstruction.

\section{CONCLUSIONS}

Symmetrical knee-extension and knee-flexion strength, a more symmetrical hop performance and higher present self-efficacy at an early stage all increased the odds of achieving symmetrical muscle function in young athletes 1 year after ACL reconstruction.

Acknowledgements The authors thank biostatisticians Bengt Bengtsson and Nils-Gunnar Pehrsson from Statistiska Konsultgruppen for help with statistical analyses.

Contributors All authors contributed to project planning. SB drafted the manuscript. All authors critically revised and approved the final version of the manuscript. All authors are responsible for the overall content as guarantors.

Funding The study was funded by grants from the Swedish Research Council for Sport Science, the Local Research and Development Board for Gothenburg and Södra Bohuslän, and by the Unit of Physiotherapy, Institute of Neuroscience and Physiology, Sahlgrenska Academy, University of Gothenburg.

Competing interests None declared.

Patient consent for publication Obtained.

Ethics approval The study was approved by the Regional Ethical Review Board in Gothenburg (registration numbers: 265-13, T023-17).

Provenance and peer review Not commissioned; externally peer reviewed.

Data sharing statement Analyses and additional data are available upon request to SB (susanne.beischer@gu.se).

Open access This is an open access article distributed in accordance with the Creative Commons Attribution Non Commercial (CC BY-NC 4.0) license, which permits others to distribute, remix, adapt, build upon this work non-commercially, and license their derivative works on different terms, provided the original work is properly cited, appropriate credit is given, any changes made indicated, and the use is non-commercial. See: http://creativecommons.org/licenses/by-nc/4.0/.

\section{REFERENCES}

1. Kyritsis $P, B a h r R$, Landreau $P$, et al. Likelihood of $A C L$ graft rupture: not meeting six clinical discharge criteria before return to sport is 
associated with a four times greater risk of rupture. Br J Sports Med 2016;50:946-51.

2. Grindem H, Snyder-Mackler L, Moksnes $\mathrm{H}$, et al. Simple decision rules can reduce reinjury risk by $84 \%$ after $A C L$ reconstruction: the Delaware-Oslo ACL cohort study. Br J Sports Med 2016;50:804-8.

3. Toole AR, Ithurburn MP, Rauh MJ, et al. Young athletes cleared for sports participation after anterior cruciate ligament reconstruction: how many actually meet recommended return-to-sport criterion cutoffs? J Orthop Sports Phys Ther 2017;47:825-33.

4. Beischer S, Hamrin Senorski E, Thomeé C, et al. Young athletes return too early to knee-strenuous sport, without acceptable knee function after anterior cruciate ligament reconstruction. Knee Surg Sports Traumatol Arthrosc 2018;26:1966-74.

5. Andernord D, Desai N, Bjornsson $\mathrm{H}$, et al. Patient predictors of early revision surgery after anterior cruciate ligament reconstruction: a cohort study of 16,930 patients with 2-year follow-up. Am J Sports Med 2015;43:121-7.

6. Webster KE, Feller JA, Leigh WB, et al. Younger patients are at increased risk for graft rupture and contralateral injury after anterior cruciate ligament reconstruction. Am J Sports Med 2014:42:641-7.

7. Allen MM, Pareek A, Krych AJ, et al. Are female soccer players at an increased risk of second anterior cruciate ligament injury compared with their athletic Peers? Am J Sports Med 2016;44:2492-8.

8. Wiggins AJ, Grandhi RK, Schneider DK, et al. Risk of secondary injury in younger athletes after anterior cruciate ligament reconstruction: a systematic review and meta-analysis. Am J Sports Med 2016;44:1861-76.

9. Schilaty ND, Bates NA, Sanders TL, et al. Incidence of second anterior cruciate ligament tears (1990-2000) and associated factors in a specific geographic locale. Am J Sports Med 2017:45:1567-73.

10. Dekker TJ, Godin JA, Dale KM, et al. Return to sport after pediatric anterior cruciate ligament reconstruction and its effect on subsequent anterior cruciate ligament injury. J Bone Joint Surg Am 2017;99:897-904

11. Nawasreh Z, Logerstedt $D$, Cummer $K$, et al. Do patients failing Return-to-Activity criteria at 6 months after anterior cruciate ligament reconstruction continue demonstrating deficits at 2 years? Am J Sports Med 2017;45:1037-48.

12. Eitzen I, Holm I, Risberg MA. Preoperative quadriceps strength is a significant predictor of knee function two years after anterior cruciate ligament reconstruction. Br J Sports Med 2009;43:371-6.

13. Logerstedt D, Lynch A, Axe MJ, et al. Pre-operative quadriceps strength predicts IKDC2000 scores 6 months after anterior cruciate ligament reconstruction. Knee 2013;20:208-12.

14. Logerstedt D, Di Stasi S, Grindem H, et al. Self-reported knee function can identify athletes who fail return-to-activity criteria up to 1 year after anterior cruciate ligament reconstruction: a delaware-oslo ACL cohort study. J Orthop Sports Phys Ther 2014:44:914-23.

15. Villa FD, Ricci M, Perdisa F, et al. Anterior cruciate ligament reconstruction and rehabilitation: predictors of functional outcome. Joints 2015;3:179-85.

16. Ithurburn MP, Paterno MV, Ford KR, et al. Young athletes after anterior cruciate ligament reconstruction with Single-Leg landing asymmetries at the time of return to sport demonstrate decreased knee function 2 years later. Am J Sports Med 2017;45:2604-13.

17. Thomeé $\mathrm{P}$, Währborg $\mathrm{P}$, Börjesson $\mathrm{M}$, et al. Self-efficacy of knee function as a pre-operative predictor of outcome 1 year after anterior cruciate ligament reconstruction. Knee Surg Sports Traumatol Arthr 2008;16:118-27.

18. Hamrin Senorski E, Samuelsson K, Thomeé C, et al. Return to knee-strenuous sport after anterior cruciate ligament reconstruction: a report from a rehabilitation outcome registry of patient characteristics. Knee Surg Sports Traumatol Arthrosc 2017;25:1364-74

19. Tegner $Y$, Lysholm J. Rating systems in the evaluation of knee ligament injuries. Clin Orthop Relat Res 1985;198:43-9.

20. Briggs KK, Lysholm J, Tegner Y, et al. The reliability, validity, and responsiveness of the lysholm score and tegner activity scale for anterior cruciate ligament injuries of the knee: 25 years later. $A m \mathrm{~J}$ Sports Med 2009;37:890-7.

21. Thomeé $P$, Währborg $P$, Börjesson $M$, et al. A new instrument for measuring self-efficacy in patients with an anterior cruciate ligament injury. Scand J Med Sci Sports 2006;16:181-7.

22. Roos EM, Roos HP, Lohmander LS, et al. Knee Injury and Osteoarthritis Outcome Score (KOOS)--development of a selfadministered outcome measure. J Orthop Sports Phys Ther 1998;28:88-96.

23. Frobell RB, Roos EM, Roos HP, et al. A randomized trial of treatment for acute anterior cruciate ligament tears. N Engl J Med 2010;363:331-42
24. Hamrin Senorski E, Svantesson E, Beischer S, et al. Concomitant injuries may not reduce the likelihood of achieving symmetrical muscle function one year after anterior cruciate ligament reconstruction: a prospective observational study based on 263 patients. Knee Surg Sports Traumatol Arthrosc 2018;26:2966-77.

25. Sole G, Hamrén J, Milosavljevic S, et al. Test-retest reliability of isokinetic knee extension and flexion. Arch Phys Med Rehabil 2007;88:626-31.

26. Ruschel C, Haupenthal A, Jacomel GF, et al. Validity and reliability of an instrumented leg-extension machine for measuring isometric muscle strength of the knee extensors. J Sport Rehabil 2015;24. doi:10.1123/jsr.2013-0122

27. Drouin JM, Valovich-mcLeod TC, Shultz SJ, et al. Reliability and validity of the Biodex system 3 pro isokinetic dynamometer velocity, torque and position measurements. Eur J Appl Physiol 2004;91:22-9.

28. Almosnino S, Stevenson JM, Bardana DD, et al. Reproducibility of isokinetic knee eccentric and concentric strength indices in asymptomatic young adults. Phys Ther Sport 2012;13:156-62.

29. Gustavsson $A$, Neeter $C$, Thomeé $P$, et al. A test battery for evaluating hop performance in patients with an ACL injury and patients who have undergone ACL reconstruction. Knee Surg Sports Traumatol Arthr 2006;14:778-88.

30. Thomeé R, Kaplan Y, Kvist J, et al. Muscle strength and hop performance criteria prior to return to sports after ACL reconstruction. Knee Surg Sports Traumatol Arthrosc 2011;19:1798-805.

31. Metz CE. Basic principles of ROC analysis. Semin Nucl Med 1978;8:283-98.

32. Concato J, Feinstein AR. Monte Carlo methods in clinical research: applications in multivariable analysis. $J$ Investig Med 1997;45:394-400.

33. Ardern CL, Taylor NF, Feller JA, et al. Fifty-five per cent return to competitive sport following anterior cruciate ligament reconstruction surgery: an updated systematic review and meta-analysis including aspects of physical functioning and contextual factors. Br J Sports Med 2014;48:1543-52.

34. Ardern CL, Taylor NF, Feller JA, et al. Return-to-sport outcomes at 2 to 7 years after anterior cruciate ligament reconstruction surgery. Am J Sports Med 2012;40:41-8.

35. Ageberg E, Forssblad M, Herbertsson P, et al. Sex differences in patient-reported outcomes after anterior cruciate ligament reconstruction: data from the Swedish knee ligament register. $A m \mathrm{~J}$ Sports Med 2010;38:1334-42.

36. Hartigan EH, Zeni J, Di Stasi S, et al. Preoperative predictors for noncopers to pass return to sports criteria after ACL reconstruction. J Appl Biomech 2012;28:366-73.

37. Bandura A. Self-efficacy: toward a unifying theory of behavioral change. Psychol Rev 1977;84:191-215.

38. Logerstedt D, Grindem H, Lynch A, et al. Single-legged hop tests as predictors of self-reported knee function after anterior cruciate ligament reconstruction: the delaware-oslo ACL cohort study. Am J Sports Med 2012;40:2348-56

39. Ericsson YB, Roos EM, Frobell RB. Lower extremity performance following ACL rehabilitation in the KANON-trial: impact of reconstruction and predictive value at 2 and 5 years. $\mathrm{Br} J$ Sports Med 2013;47:980-5.

40. Makhni EC, Crump EK, Steinhaus ME, et al. Quality and variability of online available physical therapy protocols from academic orthopaedic surgery programs for anterior cruciate ligament reconstruction. Arthroscopy 2016;32:1612-21

41. Grindem H, Granan LP, Risberg MA, et al. How does a combined preoperative and postoperative rehabilitation programme influence the outcome of ACL reconstruction 2 years after surgery? A comparison between patients in the Delaware-Oslo ACL cohort and the Norwegian national knee ligament registry. $\mathrm{Br} J$ Sports Med 2015;49:385-9.

42. Palmieri-Smith RM, Lepley LK. Quadriceps strength asymmetry after anterior cruciate ligament reconstruction alters knee joint biomechanics and functional performance at time of return to activity. Am J Sports Med 2015;43:1662-9.

43. Ithurburn MP, Altenburger AR, Thomas S, et al. Young athletes after $A C L$ reconstruction with quadriceps strength asymmetry at the time of return-to-sport demonstrate decreased knee function 1 year later. Knee Surg Sports Traumatol Arthrosc 2018;26:426-33.

44. Schmitt LC, Paterno MV, Hewett TE. The impact of quadriceps femoris strength asymmetry on functional performance at return to sport following anterior cruciate ligament reconstruction. J Orthop Sports Phys Ther 2012;42:750-9.

45. Ithurburn MP, Paterno MV, Ford KR, et al. Young athletes with quadriceps femoris strength asymmetry at return to sport after anterior 
cruciate ligament reconstruction demonstrate asymmetric Single-Leg Drop-Landing mechanics. Am J Sports Med 2015;43:2727-37.

46. Gokeler A, Welling W, Benjaminse A, et al. A critical analysis of limb symmetry indices of hop tests in athletes after anterior cruciate ligament reconstruction: a case control study. Orthop Traumatol Surg Res 2017;103:947-51
47. Wellsandt E, Failla MJ, Snyder-Mackler L. Limb symmetry indexes can overestimate knee function after anterior cruciate ligament injury. J Orthop Sports Phys Ther 2017;47:334-8.

48. Hiemstra LA, Webber S, MacDonald PB, et al. Contralateral limb strength deficits after anterior cruciate ligament reconstruction using a hamstring tendon graft. Clin Biomech 2007;22:543-50. 